\title{
La mirada alemana sobre México en tres viajeros: Alexander von Humboldt (1769-1859), Friedrich Ratzel (1844-1904) y Adolf Reichwein (1898-1944)
}

\author{
Héctor Mendoza Vargas \\ Instituto de Geografía \\ Universidad Nacional Autónoma de México \\ hvargas@unam.mx
}

La mirada alemana sobre México en tres viajeros: Alexander von Humboldt (1769-1859), Friedrich Ratzel (1844-1904) y Adolf Reichwein (1898-1944) (Resumen)

Este artículo propone la lectura de los cambios culturales en tres obras de viajeros: Alexander von Humboldt (1769-1859), Friedrich Ratzel (1844-1904) y Adolf Reichwein (1898-1944), en tres momentos, en el tránsito del mundo colonial al moderno y contemporáneo. Cada uno llevó a cabo una recopilación de información durante su viaje, en ocasiones por la exploración y prácticas científicas y en otras por miradas culturales del territorio. En sus métodos de trabajo hay una narrativa escrita, combinada con la producción de un lenguaje visual con los mapas, las fotografías y la película cinematográfica. Por lo anterior, este trabajo sitúa, a lo largo de tres apartados, los intereses alemanes hacia México por medio estos viajeros que atravesaron el país del Pacífico al Atlántico. La experiencia de estos viajes mexicanos, caracterizada por lo subjetivo, señalaba la circunstancia local en relación con contextos globales e influencias, tanto de Europa como de los Estados Unidos, vigentes a lo largo del XIX e inicios del siglo XX, sobre México.

Palabras clave: Alexander von Humboldt, Friedrich Ratzel, Adolf Reichwein, México, Alemania, viajeros.

The German perspective of Mexico from three travelers: Alexander von Humboldt (1769-1859), Friedrich Ratzel (1844-1904) and Adolf Reichwein (1898-1944) (Abstract)

This paper examines the cultural changes evident in the works of three German travelers to Mexico (Alexander von Humboldt (1769-1859), Friedrich Ratzel (1844-1904) and Adolf Reichwein (18981944). Each of these travelers compiled information collected during their trip, sometimes through exploration and scientific practice and at other times through cultural observations of the territory. Their methods included a written narrative combined with the production of a visual language of maps, photographs and motion picture film. Thus, this work examines German interests in Mexico through the perspective of these travelers who crossed the country from the Pacific to the Atlantic. The subjective experience of these Mexican travels took place in relation to local circunstances as wel as global contexts and influences from both Europe and the United States that actively shaped Mexico in the nineteenth and early tweentieth centuries. 
Key words: Alexander von Humboldt, Friedrich Ratzel, Adolf Reinchwein, Mexico, Germany, travelers

Una de las características de los viajeros extranjeros que se dirigieron a México era su entrada por las aguas del golfo de México, sobre todo en el siglo XIX, cuando el país quedaba abierto al interés de las potencias europeas y a la posible ampliación de sus influencias económicas hacia América por medio del libre comercio y la minería ${ }^{1}$. Este paso de los viajeros ha dejado una amplia literatura de autores europeos que se adentraron a partir de su llegada en barco al territorio mexicano. La ruta seguida desde el puerto de Veracruz hacia la capital mexicana ofrecía las primeras impresiones de la tierra, el clima, las montañas y la vegetación, a lo que seguían los caminos y la organización social, el puerto, las ciudades y, al final, la Ciudad de México, la nueva capital política al lado de los grandes volcanes y lagos. Un paisaje que cautivaba la mirada del viajero que, llegado por primera vez a tierra mexicana, comenzaba los contactos sociales, políticos y comerciales con la finalidad de conocer de una manera directa la apertura y el ambiente con el nacimiento de la vida independiente ${ }^{2}$.

La mirada viajera ha demostrado la amplitud y variedad de este género, tanto en el plano editorial $^{3}$ como en el análisis historiográfico que ofrece como fuente histórica ${ }^{4}$, a lo que se suman las diversas trayectorias examinadas por la geografía e historia mexicanas, por ejemplo, sobre la riqueza económica señalada por los viajeros, así como lo militar, lo espiritual, los valores, lo educativo o sobre "la construcción de la idea de lo nacional, lo mexicano y de sus singularidades" $"$. El espacio colonial también forma parte de los intereses de esta mirada ${ }^{6}$, de ahí llegan las descripciones del interior, las costas del Atlántico y del Pacífico novohispano ${ }^{7}$ y las bases naturales como los ríos, las montañas, la vegetación, sin olvidar, los temas de la sociedad, las ciudades y la cultura ${ }^{8}$. Todo esto se inscribe en el constante interés que hay por los viajeros en tierras mexicanas ${ }^{9}$. El análisis, procedente desde la literatura, ha incorporado nuevas relaciones entre el espacio, los viajes y los viajeros ${ }^{10}$.

A diferencia de esa entrada por el oriente, este trabajo centra la atención en tres viajeros que arribaron por el poniente, es decir por el Océano Pacífico. Entre los alemanes que entraron por este flanco, Alexander von Humboldt (1769-1859), Friedrich Ratzel (1844-1904) y Adolf Reichwein (1898-1944) vivieron episodios mexicanos de la política y órdenes sociales y económicos durante el siglo XIX y hasta el primer tercio del siglo XX. Cada uno hizo el viaje mexicano a una edad similar, menos de treinta años y compartieron ciertos rasgos comunes, señalados por Ernesto Livon-Grosman, como: el lugar hacia donde viajan, las referencias

\footnotetext{
${ }^{1}$ Ortega y Medina, 1987; Ortega y Medina, 1988; Jiménez, 1996.

${ }^{2}$ Covarrubias, 1998; Poblett, 2000.

${ }^{3}$ En esta perspectiva, Ramírez identifica tres periodos en la publicación de la literatura viajera del siglo XIX, inicia hacia mediados del siglo XX con la labor de Juan Ortega y Medina y su interés por los viajeros anglosajones y alemanes; sigue un periodo en los años ochenta con un proyecto mayor de libros de viajeros presentados en la colección Sepsetentas, editada por la Secretaría de Educación Pública (SEP), con títulos de viajeros europeos, algunos alcanzaron 30000 ejemplares impresos; al que se añade la colección Mirada Viajera, de los años noventa, con la traducción y transcripción de los diarios de viajeros de los siglos XVII al XX, tanto europeos como de América del Sur. Ramírez, 2013, pp. 118-119.

${ }^{4}$ Bernecker, 2003.

${ }^{5}$ Ramírez, 2013, p. 115.

${ }^{6}$ Ita, 2012.

${ }^{7}$ Pinzón, 2008; Pinzón 2009.

${ }^{8}$ Mendoza, 2007.

${ }^{9}$ Poblett, 2000.

${ }^{10}$ Zamudio, 2004.
} 
históricas con que contaron y añadieron a su narrativa, el paisaje surgido a los ojos de cada viajero, el viaje seguido por cada uno y, en general, el estudio de la zona realizado como un todo $^{11}$. En los tres viajeros elegidos en este trabajo se identifican dichos rasgos: convirtieron a América en un lugar común de viaje, se interesaron por episodios históricos, observaron el paisaje, viajaron desde el Pacífico al Atlántico y realizaron un estudio del país integrado en una obra publicada; además, cada uno contaba con apoyos diferentes para el viaje personal. Mientras Humboldt viajaba como un liberal ilustrado con los recursos de la herencia materna y el permiso oficial del monarca español Carlos IV, Ratzel lo hacía con las facilidades de un periodista enviado por un diario alemán de Colonia y, en el caso de Reichwein, viajaba como profesor universitario bajo permiso de la Universidad Popular de Jena, en Turingia.

Los tres viajeros alemanes indicados han recibido una desigual atención en cuanto al estudio de su obra y el viaje mexicano. Humboldt se ha convertido en uno de los viajeros más influyentes del siglo XIX y uno de los pensadores en la fundación de la geografía moderna, al lado de Carl Ritter ${ }^{12}$, con su trabajo integraba ejercicios de observación, de integración de información de diversa procedencia y de generalización "para confeccionar una visión completa del mundo"13. En cuanto a Ratzel, ocupó un lugar en el pensamiento geográfico de la segunda mitad del siglo XIX, por sus ideas sobre la "actividad humana en la Tierra determinada, en gran parte, por la naturaleza del entorno físico" ${ }^{14}$ Estos viajes, además, consolidaron y ampliaron los intereses de la cultura alemana en la transición del México del siglo XIX al $\mathrm{XX}^{15}$. En contraste, aquí se inserta a otro viajero alemán desconocido para la geografía e historia mexicanas. La información sobre Adolf Reichwein apenas se ha recuperado en Alemania ${ }^{16}$, aunque sus actividades y viaje por tierras mexicanas permanecen desconocidos. Hay algunas notas de Reichwein en su libro mexicano, noticias en las cartas a la familia ${ }^{17}$ e ideas de sus inquietudes por la innovación docente, la comprensión del paisaje y la valoración de la naturaleza.

Cada uno de los viajeros llevó a cabo una recopilación de información durante su viaje, nada más que por procedimientos diferentes, en ocasiones por la exploración y prácticas científicas y en otras por miradas culturales del territorio como parte de los viajes. Este trabajo examina a lo largo de tres apartados, el cambio de la cultura alemana hacia México por medio del viaje de tres alemanes que atravesaron el país de costa a costa, en tres momentos, en el tránsito del mundo colonial al moderno y contemporáneo. Se sitúa la transición de los medios culturales que aplicaron para el conocimiento del país, de la visión naturalista y científica a la del periodismo y a la expansión de la narrativa apoyada en nuevas tecnologías, además del mapa, con el uso de la fotografía y la película cinematográfica, como una innovación que actualizaba la enseñanza. Se añade, al final, los contextos globales donde circularon las obras en su momento, el contraste y la presencia cíclica de los intereses alemanes a lo largo del tiempo sobre México.

\footnotetext{
${ }^{11}$ Livon-Grosman, 2003, pp. 16-23.

12 Capel, 2012; Unwin, 1995; Claval, 1995; Holt, 1992.

${ }^{13}$ Unwin, 1995, p. 114.

${ }^{14}$ Unwin, 1995, p. 134.

${ }^{15}$ Mentz, 1982; Covarrubias, 2009; Zermeño, 2010.

${ }^{16}$ Schulz, 1966; Amlung, 1996a; Amlung, 1996b; Lingelbach y Amlung, 2011; Eckelmann, 2014.

${ }^{17}$ Wehl, 2006; Reichwein, 2011.
} 


\section{Humboldt, el expansionismo europeo y el lugar de la Nueva España}

Sobre Alexander von Humboldt se han publicado innumerables estudios, su biografía abarca diversas trayectorias personales, así como los viajes por Europa, América y Asia ${ }^{18}$. Lo atractivo de su figura origina una vasta y diversa bibliografía de una dimensión difícil de abarcar, tanto a nivel personal como por parte de los servicios bibliotecarios ${ }^{19}$, además de la digitalización de los diarios de viaje ${ }^{20}$, la edición de su agenda de $\operatorname{contactos}^{21}$ y la recuperación de sus cartas americanas ${ }^{22}$, a lo que se suman otros trabajos en América Latina ${ }^{23}$. La figura de Humboldt ha sido estudiada ampliamente en México, al igual que su viaje por una parte de las tierras novohispanas ${ }^{24}$, entre 1803 y 1804 (figura 1), también las particularidades de su obra y la recepción política a lo largo del siglo XIX y académica en el $\mathrm{XX}^{25}$.

Figura 1.

Los viajes de Alexander von Humboldt en la Nueva España

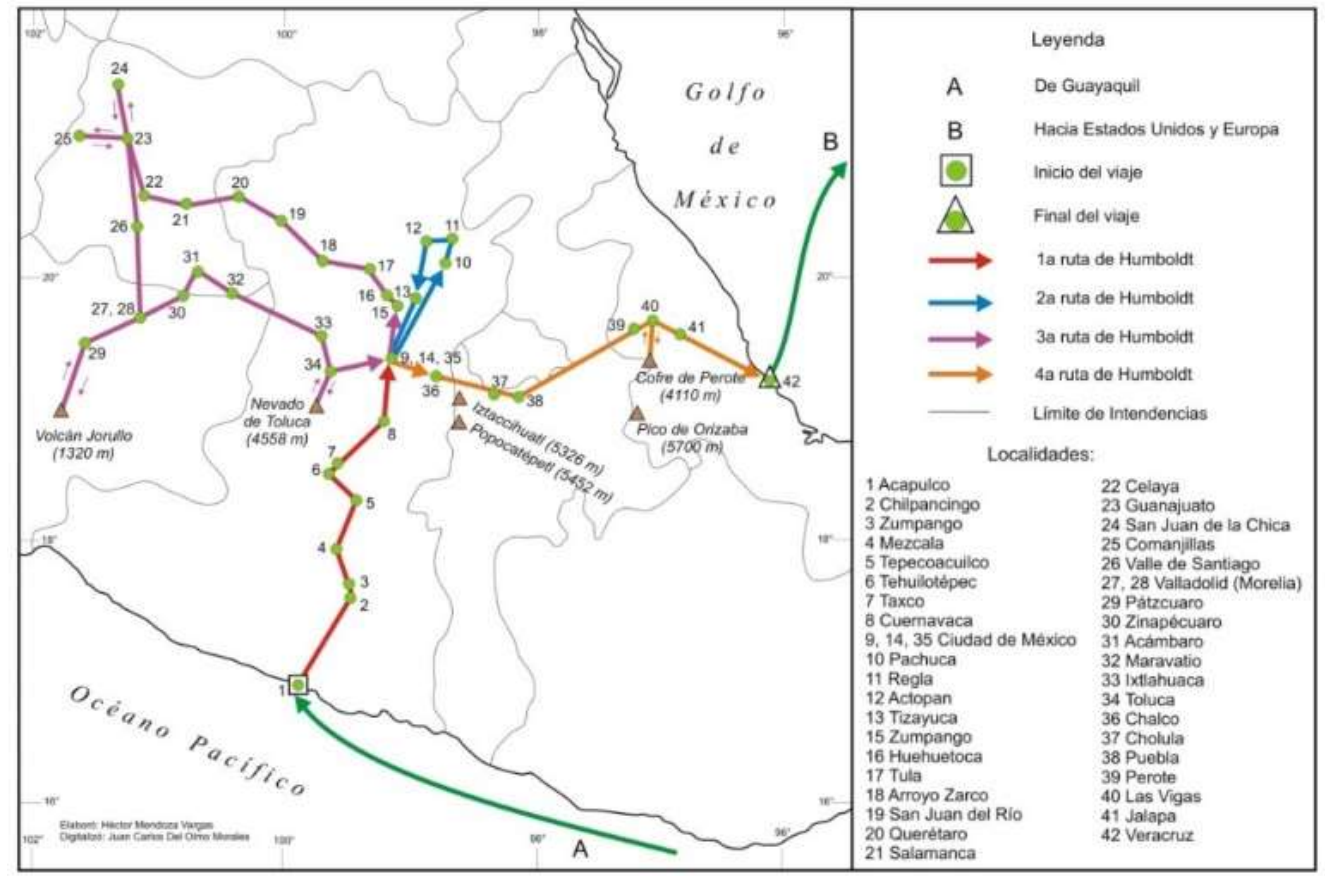

Fuente: Elaboración propia.

\footnotetext{
${ }^{18}$ Beck, 1971; Livingstone, 1993; Duviols y Minguet, 1994.

${ }^{19}$ La erudita bibliografía general que ha reunido Markus Breuning, en 2010, contaba con 9542 registros de y sobre Humboldt, lo que la convertía en la más completa hasta ese momento. Véase Breuning, 2010.

${ }^{20} \mathrm{Kraft}, 2015$. Los diarios de viaje se compraron en 2013 con un pago de 12 millones de euros a los herederos de Humboldt, la familia von Heinz de Berlín, también actuales propietarios del Palacio de Tegel.

${ }^{21}$ En la agenda de Humboldt, un volumen de 204 páginas, se encontraron en orden alfabético y anotados por él mismo, "los nombres de casi 900 personas con las que se comunicaba". Véase Kraft, 2013, p. 18.

${ }^{22}$ Humboldt, 1970; Humboldt, 1989. En esta recopilación y edición de la correspondencia, preparada por Charles Minguet, se ordenaron 162 cartas de Humboldt enviadas entre 1799 hasta 1858.

${ }^{23}$ Ita y Sánchez, 2006. A través del giro cultural se abrieron nuevas rutas de investigación, por ejemplo, se ha recuperado el lugar que ocupó el saber geográfico oral y empírico de los pobladores del Orinoco, transmitido a Humboldt e invisibilizado por él en la construcción de los mapas del Atlas pittoresque (1810). Una vertiente fascinante que ha renovado la comprensión del trabajo realizado por Humboldt en los primeros años de su viaje americano, particularmente, durante la travesía del Virreinato de la Nueva Granada. Véase Pérez, 2002. La perspectiva abierta por parte de Pérez Mejía aún no se ha elaborado para el viaje novohispano de Humboldt.

${ }^{24}$ Holl, 1997; Holl, 2003; Ita, 2006; Covarrubias, 2009.

${ }^{25}$ Azuela, 2000: Covarrubias, 2009.
} 
En esta dirección, se suman los estudios del manuscrito de las Tablas Geográfico-políticas del Reyno de la Nueva España ${ }^{26}$ y la lectura múltiple del Ensayo político sobre el reino de la Nueva España, a doscientos años de la edición de este libro, 1811-2011, a partir de la relación con la "economía mexicana a finales del siglo XVIII y comienzos del XIX"27.

Iniciado el viaje en el puerto de Acapulco, en marzo de 1803, Humboldt se instaló en el Seminario de Minería de la capital novohispana para preparar varios trabajos relacionados con los proyectos de la minería, las clases de mineralogía, las técnicas aplicadas, los problemas en las entrañas de cientos de minas del reino ${ }^{28} \mathrm{y}$, a la vez, recolectar datos e información política, económica y geográfica para la construcción de una serie de mapas, a diferentes escalas, que dieron cuerpo al Atlas geográfico y físico del Reino de la Nueva España ${ }^{29}$. Los mapas representaron para Humboldt la práctica geográfica a lo largo del viaje con la aplicación de métodos de precisión (una combinación de observaciones de topografía con astronómicas, trigonométricas y barométricas) y el uso de instrumentos científicos adquiridos personalmente y con los que se había familiarizado ${ }^{30}$.

Como resultado del trabajo personal, de las consultas y de los viajes por algunos de los distritos mineros, Humboldt contaba con la información para trazar un "cuadro político" en una obra preparada con un doble criterio: aspectos generales, seguidos de temas particulares, con cuadros estadísticos y acompañados del mencionado atlas para el análisis del territorio colonial con mapas a diferentes escalas. Las obras se situaban en el ambiente del expansionismo europeo y fijaba el lugar de la Nueva España en el escenario mundial de las materias primas y la búsqueda de nuevos mercados entre Europa y Asia. Con este propósito ordenaba el Ensayo en seis libros: el libro primero con tres capítulos (I, II y III); el libro segundo con cuatro capítulos (IV, V, VI y VII); el libro tercero con un capítulo (VIII); el libro cuarto con tres capítulos (IX, X y XI); el libro quinto con un capítulo (XII) y el libro sexto con dos capítulos (XIII y XIV).

Humboldt comenzaba su libro con las características del espacio novohispano, con esto, situaba la primera variable de la mirada alemana. Los contenidos del libro primero se orientaron al gran escenario que interesaba destacar a Humboldt: sobre la opciones para unir el Mar del Sur con el Océano Atlántico. Un desafío al talento del viajero prusiano, pues debió sumergirse en una variedad de fuentes, de archivos y datos de los ingenieros militares, además de la información que escuchaba y facilitaban las autoridades virreinales. Sobre los elementos del territorio, fijaba las condiciones naturales, es decir, las bases físicas de la vida humana, la extensión del territorio y las costas de uno y otro lado, las montañas y las llanuras. El paisaje se complicaba desde la Nueva Granada hasta la Nueva España, para él: "No hay en todo el globo paraje ninguno que esté tan erizado de volcanes como esta parte de la América"31, a lo que sumaba el análisis de la línea de costa, para detectar una serie de pasos, desde la Nueva España hasta Nicaragua y Panamá para la comunicación oceánica y la apertura de nuevos

\footnotetext{
${ }^{26}$ Trabulse, 2003; Sánchez, 2005.

${ }^{27}$ Covarrubias y Souto, 2012.

${ }^{28}$ Ortega y Medina, 1984, p. xv.

${ }^{29}$ Beck, 1971; Beck, 1987.

${ }^{30}$ El atlas corresponde al volumen XIX de la serie americana de Humboldt, contiene los lugares, las coordenadas geográficas y las consultas, realizadas por él tanto en archivos de Madrid como en la Ciudad de México. El atlas contiene los veinte mapas, perfiles y láminas, en este orden: el mapa general del reino, los mapas regionales, los mapas particulares (los puertos de Veracruz y Acapulco), ocho mapas que presenta Humboldt para el análisis de la posible comunicación entre el Pacífico y el Atlántico, los mapas de itinerarios, como el de Acapulco a la Ciudad de México y de la capital colonial a Santa Fe y varias gráficas. Véase Humboldt, 1971.

${ }^{31}$ Humboldt, 1984, p. 10.
} 
mercados $^{32}$, este era uno de los rasgos naturales que más interesaban a Humboldt del paisaje americano $^{33}$.

A este punto se relacionaba su interés en las "regiones más fértiles y más inmediatas a las costas" de la Nueva España. Humboldt se fijaba que estos paisajes se encontraban deshabitados $^{34}$. Para los españoles, indicaba en el segundo libro, era agradable habitar en las partes altas, "en las inmediaciones de la capital de México", por el clima "análogo al de su patria" y al paisaje del trigo y los árboles frutales similares a los de Europa ${ }^{35}$. Humboldt destacaba: "Ninguna ciudad del Nuevo Continente, sin exceptuar las de los Estados Unidos, presenta establecimientos científicos tan grandes y sólidos como la capital de México"36 La Ciudad de México era admirada por Humboldt, tanto por la riqueza de las familias, los edificios, las casonas, las calles limpias e iluminadas. En la Escuela de Minas se preparaban, desde 1792, a los técnicos para la minerìa que, a los ojos de Humboldt, transformaba el paisaje por la madera cortada de los bosques en las áreas próximas a las minas y por la extracción de los metales. Humboldt registraba esta actividad en los mapas y estadísticas del Ensayo, con lo que dejaba abierto el potencial del paisaje minero con datos precisos requeridos para la inversión extranjera.

En las estadísticas, objeto del libro tercero, Humboldt examinaba la dispersión de la población. San Luís Potosí, México o Guanajuato eran las intendencias más pobladas y señalaba la desproporción que había con respecto a las provincias de enorme extensión y despobladas como Texas, Coahuila y Nuevo México. Este punto, para él, requería el cambio de tamaño y nuevos límites de las intendencias, a partir del "estado físico y agrícola" de cada una. Consideraba, en beneficio de la administración, una relación proporcional entre la población y el territorio, como en el modelo político francés, que consideraba útil para la Nueva España ${ }^{37}$. Estos cambios se relacionaban, por el lado del Pacífico y su larga línea de costa, con el potencial comercio y de negocios con China y la India; además de los posibles intercambios de las islas del Pacífico, una vez que "las costas comiencen a poblarse" en San Luis Potosí, Veracruz, Yucatán, así como en California, Sonora, Guadalajara, Valladolid, México, Puebla y Oaxaca.

La agricultura, vista por Humboldt, relacionaba la enorme superficie, los climas y las montañas que, en conjunto, marcaban la vida vegetal y su distribución, tema del libro cuarto; para él, las tierras más fértiles se encontraban abandonadas ${ }^{38}$, excepto en el paisaje de Guanajuato, Zacatecas, San Luis Potosí y Durango donde se encontraban las minas y una variedad de cultivos que formaban la base de la alimentación del pueblo, eran paisajes cerealeros: el trigo, el centeno, la cebada y la avena ${ }^{39}$, así como la papa oca y el camote o boniato, las verduras, los árboles frutales de Europa y el maguey. A este cuadro se sumaba el azúcar, el café, el cacao, la vainilla, el tabaco, el añil o índigo y el algodón de interés para la importación al mercado europeo. En este cuadro entraba, para terminar, el ganado bovino, los carneros, el cerdo, las aves domésticas o de corral: las gallinas y pavos; los gusanos de seda, la oruga y la cochinilla; también la pesca de perlas y la ballena ${ }^{40}$. Situaba a la minería, dentro

\footnotetext{
32 Pinzón, 2012.

${ }^{33}$ Humboldt, 1984, p. 7.

${ }^{34}$ Humboldt, 1984, p. 35.

${ }^{35}$ Humboldt, 1984, p. 35.

${ }^{36}$ Humboldt, 1984, p. 79.

${ }^{37}$ Humboldt, 1984, p. 108.

${ }^{38}$ Humboldt, 1984, p. 237-238.

${ }^{39}$ Humboldt, 1984, p. 271.

${ }^{40}$ Humboldt, 1984, p. 310.
} 
de este largo apartado, como un sector con la mayor atención de la corona española desde el siglo XVI y, de forma exclusiva, en el oro y la plata. Esta situación llamaba su atención en la Nueva España, por su experiencia directa:

Habiendo sido mi ocupación desde mi juventud el estudio del arte de beneficiar las minas, y habiendo dirigido por espacio de muchos años yo mismo las obras subterráneas en una parte de Alemania que contiene una gran cantidad de minerales, he debido tener doble interés en examinar con cuidado el estado de las minas y de los métodos de beneficiarlas en Nueva España ${ }^{41}$.

Así, Humboldt pasó a visitar los paisajes mineros de Taxco, de Pachuca y, sobre todo, de Guanajuato donde examinaba el ancho de 40 a 45 metros de la veta madre. La riqueza minera del reino novohispano examinada por Humboldt, en particular el oro y la plata, creaba expectativas entre los europeos. Humboldt, además, recomendaba poner atención a la agricultura ya que su "valor crece con el tiempo" ${ }^{42}$. Esta opinión se ampliaba al mundo de las manufacturas y el comercio, objeto del libro quinto, que abonarían "gran prosperidad", una vez rotas las influencias de la metrópoli ${ }^{43}$ y el arreglo de los caminos más importantes para el comercio de Veracruz y Acapulco con la capital novohispana y desde ahí hacia Puebla y Xalapa, a Chilpancingo, a Oaxaca y Guatemala, a Durango y Santa Fe en Nuevo México, además de los caminos hacia San Luis Potosí, Monterrey, Valladolid y Guadalajara. Todo esto podía beneficiar a los comerciantes de la Ciudad de México, que ejercían un fuerte monopolio y competían con los del puerto de Veracruz.

Humboldt indicaba para la recaudación, en el libro sexto, la apertura de los puertos, la colonización de chinos y malayos en las costas del Pacífico, así como una mayor atención a la agricultura del algodón, café y caña de azúcar. En suma, un equilibrio entre los productos de la minería y de la agricultura, para él, traería el aumento de la producción y el comercio, lo que transformaría el paisaje de la América española ${ }^{44}$. Terminaba su libro con una síntesis de cada uno de los apartados, antes indicados, con el vivo deseo de que su obra fuera de utilidad a la "prosperidad pública" y el cambio en el trato a los humillados del orden social para que participen de los "progresos de la civilización".

\section{Ratzel, el afán expansionista de los Estados Unidos y México}

La figura de Ratzel, al igual que la de Humboldt, ocupa un lugar de primera fila en la cultura alemana, particularmente de la segunda mitad del siglo XIX ${ }^{45}$. Este geógrafo de Karlsruhe vivió una época de profundos cambios y hacia 1871, a la edad de 27 años, era testigo de los inicios de la institucionalización de la geografía alemana, vista por el Estado por su potencial educativo en la difusión de las ciencias, la educación del público, en general y, más importante, la transmisión de ideas políticas como las ambiciones nacionalistas ${ }^{46}$. En los viajes entre Marsella y Niza y de Génova a Florencia, Roma, Nápoles, Mesina, Palermo y Catania, en 1869, se fijaba en varios temas: las migraciones, la cultura y las "relaciones entre el hombre y los factores de su entorno físico" $"$. Eran los inicios de los conceptos de espacio

\footnotetext{
${ }^{41}$ Humboldt, 1984, p. 320-321.

${ }^{42}$ Humboldt, 1984, p. 445.

${ }^{43}$ Humboldt, 1984, p. 449.

${ }^{44}$ Humboldt, 1984, p. 551.

45 Bassin, 1987, Livingstone, 1993, Unwin, 1995, Capel, 2012.

${ }^{46}$ Sandner y Rössler, 1994, p. 116.

${ }^{47}$ Zermeño, 2010, p. 164.
} 
vital (Lebensraum), poder mundial (Weltmacht) y frontera (Grenzen) ${ }^{48}$. Mientras se interesaba en el estudio de la teoría de la evolución de las especies de Charles Darwin ${ }^{49}$ y de la geología y la paleontología con Carl Alfred de Zittel, en Múnich, Ratzel recibió la oferta para convertirse en corresponsal de viaje del diario Kölnischen Zeitung de Colonia.

En este contexto y a cargo de la sección de ciencias naturales de este diario, era enviado a los Estados Unidos, para un viaje desde Nueva York hasta la costa de California ${ }^{50}$. Se dirigió a Massachusetts (para visitar la Universidad de Harvard en Cambridge) y, por la costa este, hasta la Florida y Nuevo Orleans para ascender por el río Misisipí hasta las cataratas del Niágara y de regreso a Chicago para seguir, en el ferrocarril, por las grandes planicies hacia Denver y luego hasta San Francisco. Ratzel quedaba deslumbrado del dinamismo de los habitantes, llegados apenas un siglo atrás; admiraba la industria instalada en el norte, los ferrocarriles que atravesaban el país de costa a costa con miles de kilómetros de vías férreas, las nuevas ciudades y el poblamiento de la costa del Pacífico, todo eso eran las señales de la reconstrucción del país, luego de la guerra civil (1861-1865), terminada unos años antes de la visita de Ratzel ${ }^{51}$.

En San Francisco, California, Ratzel abordó un barco de la Pacific Mail Steamship Company para México, en dirección hacia el puerto de Acapulco, el mismo que vio la llegada de Humboldt, setenta años atrás. Ahí arribó al puerto el 16 de octubre de 1874, los nuevos escenarios desafiaron la mirada de Ratzel, pasaba de la admiración por la naturaleza "casi intacta" a la vida social, calificada bajo el rigor de los ojos europeos y la acelerada experiencia que vivió en los días previos en los Estados Unidos. Este viaje le dio a Ratzel los elementos del libro: Desde México. Apuntes de viaje de los años 1874-1875 [Aus Mexico. Reiseskizzen aus den Jahren 1874 und 1875], publicado a solo tres años del regreso a Alemania por la editorial J. U. Kern's Verlag (Max Müller) de Breslau (hoy Wroclaw). La obra se situaba en el ambiente del expansionismo de los Estados Unidos de la segunda mitad del siglo XIX y, a la vez, de la construcción del imperialismo alemán y legitimación de estrategias agresivas e imperiales ${ }^{52}$. Ratzel experimentaba, a la vez, la circulación de las ideas de Darwin sobre la "relación entre las poblaciones y el medio en que viven",53 que, llevada dicha relación a su pensamiento y a la forma de entender "el espacio en el destino de los pueblos", equivalía al dominio de unos países sobre otros y a la justificación del expansionismo alemán, como se verá más adelante, en América. La obra se divide en 17 secciones o libros y 57 capítulos, donde se combinaban tanto las impresiones del viaje, las observaciones del paisaje y las reflexiones de Ratzel sobre el país en relación con las influencias de los Estados Unidos, todo eso, luego de una visita mexicana de seis meses, entre octubre de 1874 y abril de 1875 (figura 2).

Ratzel trazaba, al inicio, las características del espacio y, esta vez, sumaba la variable temporal, es decir la "antigua cultura" y la historia. Por eso, se fijaba que la posición geográfica frenaba la expansión de los Estados Unidos por el sur ${ }^{54}$. Bajo esta variable, la minería era otro de los "tesoros de sus montañas", a la que se sumaba la "naturaleza tropical": los bosques, montañas y valles con "gran cantidad de fruta tropical que no había visto

\footnotetext{
${ }^{48}$ Seemann, 2012.

${ }^{49}$ Stoddart, 1986; Bassin, 1987.

${ }^{50}$ Seemann, 2012.

${ }^{51}$ Seemann, 2012.

${ }^{52}$ Sandner y Rössler, 1994, p. 115.

${ }^{53}$ Unwin, 1995; Capel, 2012; Claval, 1995.

${ }^{54}$ Ratzel, 2009, p. 47.
} 
nunca" $" 55$. Acapulco mantenía su influencia por el camino de tierra adentro a la capital mexicana, a pesar de que era intransitable y formaba parte de una línea de puertos abiertos con Mazatlán, Manzanillo, Puerto Ángel y Salina Cruz. Este capítulo terminaba con el clima y la insalubridad del puerto del Pacífico, de momento, nada más se quejaba del calor, pues el puerto estaba protegido por la "cercanía de las montañas al mar"

Figura 2.

Los viajes de Friedrich Ratzel en México

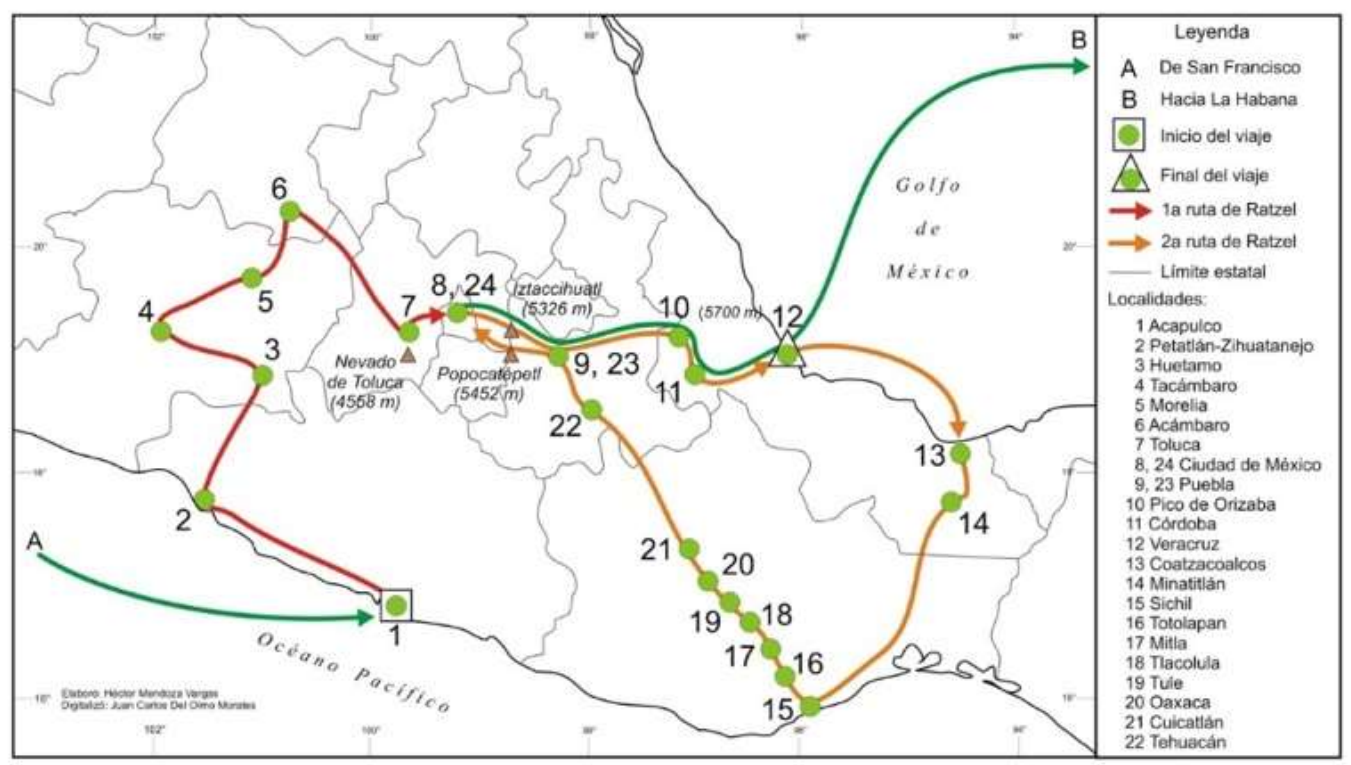

Fuente: Elaboración propia.

Los siguientes dos capítulos los dedica al viaje de Acapulco hacia Morelia y, después, a la llegada a la Ciudad de México. Tras doce días, para llegar a Morelia, reflexionaba sobre el "medio indómito" y la organización social. Al dejar la orilla del mar, montado en una mula, llamó la atención del viajero que la montaña estaba "mucho menos poblada" y el cambio de la vegetación, atrás quedaba la selva tropical y se adentraba a los bosques de robles, para él, unas reservas de madera "casi intactas",57. De la pobreza de los pueblos de la costa, Ratzel pasaba a las haciendas productoras de mezcal, un aguardiente de alta graduación y a las haciendas con "mucha cría de ganado y poca agricultura" en la parte montañosa ${ }^{58}$.

Al privar una temperatura más fría, Ratzel observó que los hombres de la montaña carecían de la "holgazanería tan paradisíaca [...] como en la región cálida", por lo que nota que las viviendas estaban construidas con adobes. Bajo esta lógica geográfica, Ratzel pensó que hacia el interior del país la situación cambiaría porque, para él, "el clima permite un trabajo más esforzado". Sin embargo, no sucedió como imaginó, las condiciones económicas y la "masa del pueblo" estaban en peor estado que en la costa. Para él, por tanto, más que el clima, "la pereza y la falta de aspiraciones" $" 59$ eran el origen de la pobreza y la falta de perspectivas del pueblo mexicano. En este punto, Ratzel expresaba una idea de civilización presente en Europa según la cual los países ricos se auto presentaban como ordenados y trabajadores

\footnotetext{
${ }^{55}$ Ratzel, 2009, p. 67

${ }^{56}$ Ratzel, 2009, p. 71.

${ }^{57}$ Ratzel, 2009, p. 88.

${ }^{58}$ Ratzel, 2009, p. 100.

${ }^{59}$ Ratzel, 2009, p. 105.
} 
(civilizados), con lo que legitimaban una construcción cultural e imperial para dominar el mundo, a los países que no "trabajaban de forma disciplinada" en la transformación del mundo natural y el dominio de los ciclos vitales de la naturaleza por parte del hombre ${ }^{60}$.

En el camino a la Ciudad de México, desde Morelia, Ratzel miraba desde la diligencia el paisaje de "buenos cultivos de maíz y trigo", antes de llegar a Toluca. En un capítulo describe el valle de México y los "imponentes" bosques de oyameles y abetos de las montañas circundantes, parecidos a las "coníferas californianas" que había visto antes, por lo que este paisaje le parecía "único e incomparable" ". En otro capítulo, se detiene en los alrededores con Chapultepec y el paisaje de los campos irrigados del trigo o del maíz de temporada que se extendían, entre agaves y nopales, con los pinos dispersos y las montañas de la región.

La mayor atención concedida a la capital mexicana le disgustaba, en detrimento de otras ciudades del país. Se fijaba más en su historia antigua, para él, por el poder unificador de los pueblos y que distingue a unos de otros y menos en la pobreza y el desorden de la ciudad ${ }^{62}$. Paseaba del Zócalo a la Alameda y criticaba la traza debido a la estrechez de las calles y a la ausencia de una "imponente arteria vial, la rica, ancha y animada avenida principal" 63 que alegraba los paseos de las ciudades europeas. Le disgustaba la limpieza deficiente de las calles; a veces, resaltaba ciertos paisajes como el Zócalo y las casas con luz y aire adaptadas al clima templado ${ }^{64}$. Se detuvo en varios edificios, entre iglesias y escuelas, frente a la Catedral, admiraba las torres y las puertas, y el frontispicio del Palacio de Minería ${ }^{65}$. Se preguntaba, finalmente, sobre la importancia de la Ciudad de México para el país, sobre todo, por el lugar preponderante entre las demás y las tecnologías que disponía como el telégrafo y el ferrocarril al puerto de Veracruz, un modelo territorial diferente al alemán, que conocía, donde ninguna ciudad dominaba sobre otras.

Los siguientes seis libros se dedicaron a la parte más larga del viaje, una combinación de itinerarios por el interior del territorio y el mar, entre montañas y bosques, entre selvas tropicales y ríos, además de una variada organización social y cambios en el paisaje. Puebla le gustó más como ciudad y sus calles las llegó a comparar con el "ordenado confort" de una ciudad alemana media, hizo una escala para ascender el Pico de Orizaba, algo que Humboldt no se propuso. Desde el puerto de Veracruz se trasladó en barco de vapor a Coatzacoalcos y seguir el viaje a Minatitlán. De Tehuantepec a Oaxaca, con una parada en las ruinas arqueológicas de Mitla y en la capital oaxaqueña antes de seguir a Tehuacán, Puebla y, de nuevo, la entrada a la Ciudad de México donde terminaba la narración de su viaje.

En los siguientes capítulos, los últimos cinco del libro, Ratzel cambió la narración hacia los puntos que más le interesaban del viaje mexicano: precisar la influencia de los Estados Unidos sobre México y definir las opciones de México como destino de los alemanes. Para esto, los temas se dividieron en dos partes: las condiciones sociales (la educación, la historia mexicana y la colonización) y la naturaleza (las plantas, las flores, los bosques y la selva tropical). Ratzel era implacable en criticar tanto las herencias coloniales, como la influencia de la iglesia católica y, en ese momento, la dificultad para ganarse la vida, la inseguridad en la

\footnotetext{
${ }^{60}$ Este punto de vista eurocentrista y colonialista con que se auto presentan impide a los alemanes "una apreciación adecuada de la realidad mexicana". Véase Radkau, 1982, p. 328-329.

${ }^{61}$ Ratzel, 2009, p. 126.

${ }^{62}$ Ratzel, 2009, p. 139.

${ }^{63}$ Ratzel, 2009, p. 139.

${ }^{64}$ Ratzel, 2009, p. 140.

${ }^{65}$ Ratzel, 2009, p. 143.
} 
ciudad y el impulso a la educación contrastaba con el arraigo social a la lotería, las rifas, las corridas de toros, las peleas de gallos y los juegos de azar ${ }^{66}$.

A Ratzel le llamaban la atención los territorios despoblados y las opciones que había para la colonización alemana. Sin embargo, este asunto se complicaba para él por dos razones: la adaptación al clima y las condiciones sociales y económicas de México. Descartada la llegada de alemanes por estos elementos ${ }^{67}$, Ratzel pasaba a considerar la posición de los Estados Unidos con México. Para él, apoyado en su viaje por California, lo mejor era el expansionismo sobre los estados mexicanos fronterizos y los de la costa del Pacífico ${ }^{68}$. Los Estados Unidos le parecieron "más idóneos que cualquier pueblo europeo, para acabar de incorporar a México a la civilización, en parte a través de la violencia y, en parte, mediante la inteligencia y la actividad"69, lo que representaba una doble vía: la intervención militar o la influencia por otros medios técnicos y económicos. La obra de Ratzel, al final, representaba el aviso para el giro del expansionismo alemán y su traslado a las tierras de América del Sur, donde ingleses y alemanes llevaron sus influencias, la colonización y las estrategias imperiales en la segunda mitad del siglo XIX.

\section{Reichwein, el interés alemán y México}

La personalidad de Adolf Reichwein perteneció a una época de austeridad y desafíos en el seno de la República de Weimar. Iniciaba el siglo XX con la propagación del imperialismo alemán con una política de "hegemonía y conquista" con la que participaron en la I Guerra Mundial $^{70}$. La derrota del imperio alemán en esta guerra dejaba una Europa devastada, con más de diez millones de alemanes en el extranjero y el trazo de las nuevas fronteras en el Tratado de Versalles (1919). Los mapas mostraban el "dolor y la experiencia traumática"71, en los años veinte y treinta, ante el desmembramiento del cuerpo alemán. Reichwein, inmerso en este contexto, egresaba de un centro secundario e ingresaba a la infantería de reserva en Varsovia, luego participó en las operaciones del frente occidental, a los 18 años de edad y, casi al final, era herido gravemente en el pulmón en Francia, por lo que regresaba a Alemania. El 4 de mayo de 1918 se inscribió en los estudios de historia y filosofía de la Universidad de Fráncfort del Meno y, dos años después, se trasladaba para estudiar historia, lenguas y artes en la Universidad de Marburg, para terminar, el 15 de febrero de 1923, con el doctorado. A partir de este año y hasta 1929 Reichwein reflexionaba la actualidad social alemana, la aplicación de la economía política y una vocación personal y política de corte socialista, a la vez, actuaba en esos años como el director del Colegio comunitario de Jena, una organización abierta para la educación, entre saberes teóricos y prácticos, para el proletariado, campesinos, emigrantes y mujeres que no tenían acceso a la educación en la región de Turingia.

En ese lugar, Reichwein encabezaba una práctica pedagógica renovada dirigida a la actualización de la labor docente, entre los profesores, a través de ejercicios y prácticas fuera del aula y en contacto con la naturaleza por medio de viajes con los alumnos a los paisajes de los bosques, de la montaña y a los campos de trigo donde enseñaba el trabajo de los

\footnotetext{
${ }^{66}$ Ratzel, 2009, p. 358-359.

${ }^{67}$ Ratzel, 2009, p. 398.

${ }^{68}$ Ratzel, 2009, p. 400.

${ }^{69}$ Ratzel, 2009, p. 400.

${ }^{70}$ Schlögel, 2007, p. 294.

${ }^{71}$ Schlögel, 2007, p. 295. Schlögel señala la discusión, entre los alemanes, sobre los resultados humillantes de la guerra, convertida en un "discurso cartográfico" que canalizaba "revulsiones etnográficas y territoriales de gran magnitud con miras a trazar de nuevo el «mapa etnográfico» de Europa”, Schlögel, 2007, p. 295.
} 
campesinos, con lo que ponía en práctica los estudios de la economía política, la geografía regional y la literatura. Reichwein usaba la película cinematográfica como un nuevo recurso pedagógico relacionado con las salidas para el registro de la vida rural. Con esas bases, entre 1926 y 1927, Reichwein llevó a cabo una serie de viajes, primero a Inglaterra y luego a Canadá y Alaska para seguir, de enero a mediados de marzo de 1927, a Japón, China y Filipinas, y de abril a junio del mismo año, entre Seattle, California y México.

Se sabe muy poco del viaje mexicano de Reichwein, hay algunas señas recuperadas por su hijo, a partir de las cartas enviadas por él a su familia y amigos ${ }^{72}$. Desde Seattle, Reichwein viajó, en abril de 1927, en automóvil a San Francisco y a Los Ángeles, ahí vendió el coche, para seguir el viaje en barco a Manzanillo ${ }^{73}$. Con su llegada a este puerto, a principios de mayo, Reichwein entraba al núcleo de la guerra cristera ${ }^{74}$. De ahí se dirigió a Tecomán y a Colima y, finalmente en Tonila, Jalisco, se encontró con Winfried Koehler (Köhler) ${ }^{75}$. Muy cerca de ahí y a trote de caballo, se extendía la hacienda La Esperanza, propiedad del alemán Enrique Schöndube (1861-1927) ${ }^{76}$. Este hacendado y su familia eran bien conocidos, había hecho su fortuna desde tiempo atrás a través del suministro de electricidad a la ciudad de Colima $^{77}$, contaba con 66 años de edad y mantuvo a su propiedad y trabajadores al margen del pleito religioso asentado en las faldas del volcán de Colima. Es posible pensar la presencia de Reichwein en la hacienda de Schöndube, ahí encontraba el mundo rural que tanto le interesaba, el rancho y el trabajo de los campesinos, la producción, los cultivos, las tierras, los sueldos y las técnicas aplicadas.

Sin embargo, se precipitaron los acontecimientos en poco tiempo. Por una parte, Reichwein estaba metido en los escenarios de la insurrección de los campesinos católicos que atacaban a los militares en Tonila ${ }^{78}$. Por otro lado, Schöndube murió sorpresivamente en el patio de la hacienda, el 12 de mayo de 1927, a manos de uno de los ex trabajadores de la hacienda,

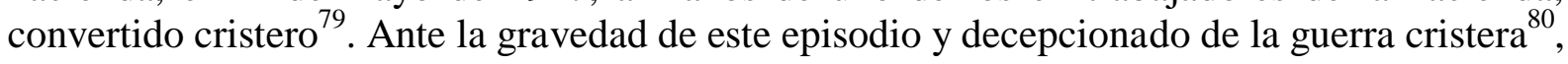

\footnotetext{
${ }^{72}$ Wehl. 2006; Reichwein, 2011.

${ }^{73}$ Una de las rutas de vapores pasaba por Mazatlán, Manzanillo, Acapulco y Salina Cruz. Véase Martínez, 1928.

${ }^{74}$ La guerra cristera era un movimiento armado entre la Iglesia católica y el Estado mexicano, en los estados de Jalisco Michoacán, Colima, Aguascalientes, Nayarit y Zacatecas, donde los "cristeros se enfrentaron al ejército y auxiliares bajo la forma de guerrillas, llegando a controlar intermitentemente algunos pueblos, y obteniendo importantes apoyos de buena parte de la población”. Véase López, 2011, p. 39.

${ }^{75}$ Reichwein representa una nueva figura alemana, en el escenario de los pueblos del sur de Jalisco y norte de Colima, dentro del giro hacia el microanálisis de los estudios. Véase Preciado, 2008; López, 2011.

${ }^{76}$ Schöndube había modernizado la hacienda La Esperanza, amplió su extensión hasta las 4800 hectáreas, desde una colina dominaba el paisaje rural con el majestuoso volcán de Colima de fondo.

77 La empresa fundada por él, en 1914, se llamaba Compañía Hidro-Eléctrica Occidental S. A., y "prestó servicios de alumbrado" al gobierno de Colima y de tranvías eléctricos en la capital, por medio de un contrato por 99 años, los “primeros 30 años, no se cobrarían impuestos a la empresa”. Véase Preciado, 2008, p. 86.

${ }^{78}$ Reichwein, 2011, p. 20. Las batallas de los cristeros, desde luego, no eran los campos de batalla europeos que Reichwein conoció muy bien. En el ejército católico participaron rancheros con las armas utilizadas en la cacería: "carabinas calibre 38, 32-20, 44 o 30-30, carabinas de retrocarga o de taco; pero ningún máuser, ni siquiera viejo o en mal estado, todas por lo general, con ocho a diez cartuchos cada una". Véase Preciado, 2008, p. 81. A lo que se sumaron la "indisciplina, desorganización, e incapacidad militar" en muchas situaciones locales tanto de los jefes como de los sacerdotes al frente de los campesinos. Véase: López, 2011, p. 48.

${ }^{79}$ Ante la negativa de Schöndube de proporcionar la dinamita, conservada en la hacienda, que le pidió Félix Ramírez para volar el tren de Guadalajara, como parte de los golpes de los cristeros al gobierno federal. Véase Preciado, 2008, p. 83.

80 Sobre las operaciones militares y los fines de la cristiada en esta región, Reichwein recordaba: "eran sublevaciones campesinas, capitaneadas en parte por sacerdotes. Sus víctimas no sospechaban nada de la verdadera realidad por la que morían; se les fanatizaba por motivos de sentimiento, y explotando su ignorancia,
} 
se pierde el rastro de Reichwein por México y, se puede pensar, a él mismo le interesaba desaparecer las pistas de su camino ante la represión oficial. Se abrieron dos opciones para alejarse de ahí, siempre acompañado de Koehler, en coche a Morelia o bien por ferrocarril a Guadalajara en dirección a la capital mexicana para continuar a Puebla, Córdoba, Veracruz y Tampico (figura 3).

Figura 3.

Los viajes de Adolf Reichwein en México

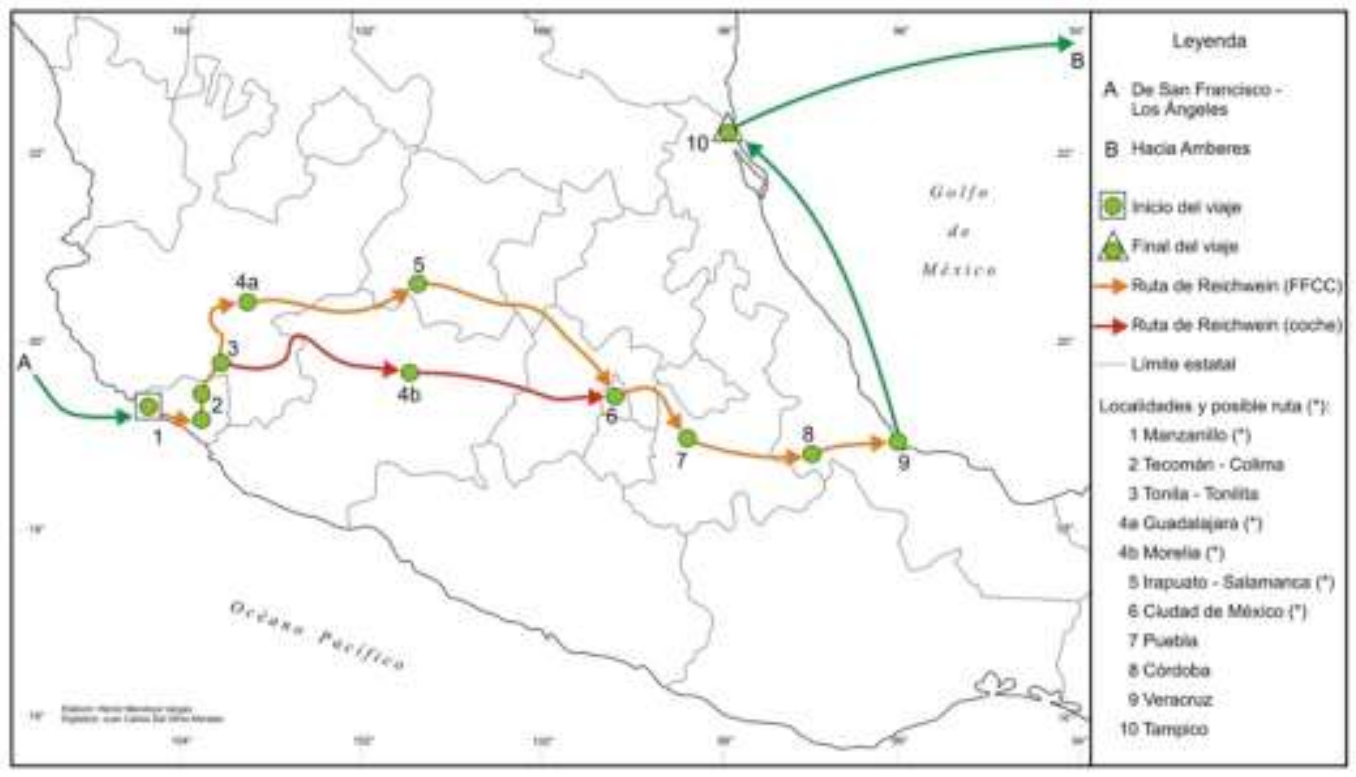

Fuente: Elaboración propia.

El viaje mexicano, además, le permitió la preparación de varios trabajos de su interés en el ámbito rural: la cosecha del maíz y la preparación del pulque ${ }^{81}$. Además, contaba con una variable novedosa de viaje: la producción de varias películas cinematográficas con la cámara de 16 milímetros, un formato para aficionados, en blanco y negro y silente, de la empresa Eastman Kodak. Reichwein dio un giro dinámico y visual con sus películas a la enseñanza del paisaje rural que, en el caso de México, era capturado para su reproducción ante los profesores y alumnos de Jena. Una de los trabajos de Reichwein se tituló: "Maisernte in Mexiko", era una grabación, con una duración de 7 minutos y 50 segundos, que mostraba al campesino en la cosecha del maíz, en mayo de 1927, en unos campos de las "tierras altas" de México, desde donde se apreciaba, al fondo, el nevado Pico de Orizaba ${ }^{82}$.

El viaje mexicano dio origen a su libro: Mexico erwacht, publicado en Leipzig en 1930 y de inmediato también en España bajo el título: El despertar de Méjico, con la traducción de Emilio R. Sádia, para la Editorial Cenit ${ }^{83}$. La obra de Reichwein se situaba en las crisis de la

se les utilizaba para los fines políticos de la Iglesia. Aquel «Viva Cristo Rey», que repercutía desde las estribaciones del volcán [de] Colima, todavía resuenan espantosamente en mis oídos”. Reichwein, 1931, p. 238.

${ }^{81}$ Lingelbach und Amlung, 2011.

${ }^{82}$ Reichwein, 1936. La película, recuperada en 1936, sería adquirida muchos años después en una subasta por Norbert Kissel, director de la ARS, en Pohlheim, en la digitalización se intercalaron los textos entre las escenas y se añadió el "Cielito lindo", una música tradicional mexicana interpretada por él mismo en el piano.

${ }^{83}$ Cenit era una editorial fundada en Madrid, en 1928, por Rafael Giménez Siles y con el apoyo de Antonio Gracó Marsá Vancells y Juan Andrade, todos, jóvenes izquierdistas con el apoyo económico de Diego Hidalgo, un "acaudalado notario" pro soviético. Esta editorial era el centro difusor de la "joven intelectualidad revolucionaria europea", en medio de las dificultades de los años veinte, desde el final de la "Monarquía de Alfonso XIII y todo el periodo revolucionario". Véase Santonja, 1983-1984, p. 129. La obra de Reichwein llegó 
República de Weimar, en los años veinte y las graves dificultades sociales, económicas y políticas. Una época de la cual Europa tampoco escapaba y era el preámbulo de la llegada de los gobiernos fascistas en Italia y Alemania que asumieron políticas económicas centralizadas, autoritarias y de inversión en la industria militar. Por eso, Reichwein anotaba en el "Prólogo" del libro: "La existencia de Europa está amenazada por el desmoronamiento de su orden social y el creciente poderío autónomo de los continentes que ella colonizó en otro tiempo" ${ }^{\text {}}$. Y añadió de manera definitiva: "Se ha quebrantado la posición prepotente de Europa, su fuerza para dictar" ${ }^{\natural 5}$. Reichwein se refiere al auge económico, la nueva posición y la expansión de los Estados Unidos, sobre todo, en la región latinoamericana y, de manera particular, sobre México que la política comercial alemana intentaba atraer a su influencia.

El libro de Reichwein se divide en nueve capítulos y se acompaña de 15 mapas y 48 fotografías en blanco y negro. ${ }^{86}$ Lo primero que presentaba Reichwein era una "ojeada de conjunto”, un capítulo que abre la pregunta central: “¿Qué es hoy, para nosotros, México?”. Aquí se encierran los temas de alto interés para Alemania. México era un país que luchaba por la producción del petróleo y se había levantado contra la iglesia católica. Ambos procesos causaban asombro en Europa y, por eso, el autor pasaba a revisar el marco general y amplio que enmarcaba la vida americana, a partir de una base común: la doctrina Monroe (1823), un dictado de los Estados Unidos que anunciaba: "América había de pertenecer a los americanos" $"$. Con esto, se cerraba la injerencia europea en los países americanos que buscaban la libertad, al menos, hasta finales del siglo XIX cuando se dio paso a otra manera de interpretar dicha doctrina. Los Estados Unidos se encumbraron como potencia industrial, consolidaron un imperialismo y exportaron grandes cantidades de capital. Reichwein examinaba los datos, para 1924, en millones de dólares: hacia Europa, 1 900, Asia y Oceanía, 690. América Latina, 4040 y Canadá, $2460^{88}$. No quedaba duda, comentaba Reichwein, México se encontraba en el "punto más álgido" de la nueva "expansión capitalista de los Estados Unidos" y, justo en este momento, el interés alemán y de los europeos significaban un equilibrio en la repartición y actuación de los poderes extranjeros en América.

Sin embargo, a la doctrina Monroe, le siguió la Unión Panamericana que, en el primer cuarto del siglo XX y establecida en Washington, favorecía la expansión económica y la misión civilizadora de los Estados Unidos, a través de una red de cables submarinos y líneas de vapores de empresas de este país que conectaban todos los puntos importantes de América Latina con Nueva York, Nueva Orleáns y San Francisco. En este contexto, al que llegaba Reichwein con su viaje, se reconocía que los países de la región habían alcanzado una estabilidad que interesaba a los Estados Unidos, pues ya no eran países "rivales, sino amigos y colaboradores" que formaban una "unidad en la política universal" $"$. México, por su parte, se encontraba en plena "estabilización y reconstrucción social de tipo liberal", un momento de

a Madrid a través del editor Wieland Herzfelde, director de la editorial Malik-Verlag, de Berlín, que buscaba ceder la exclusiva a una editorial de izquierda para las traducciones al español de "varios famosos escritores de vanguardia: Upton Sinclair, Henri Barbusse, Egon Erfwin Kisen, Máximo Gorki, Cholojov e Ignacio Silone". Véase Santonja, 1983-1984, p. 134. En este contexto editorial se entiende la incorporación de la obra de Reichwein al catálogo de Cenit que, en el transcurso de su corta vida, entre 1928 y 1936, publicó más de 200 títulos de los autores más prominentes de la izquierda europea.

${ }^{84}$ Reichwein, 1931, p. 5.

${ }^{85}$ Reichwein, 1931, p. 5.

${ }^{86}$ Entre las páginas del libro hay fotografías de Ewin S. Galloway (1881-1953), Hugo Brehme (1882-1954) y

Franz Otto Koch (1905-1940), además de otras de la empresa Publishers Photo Service de Nueva York.

${ }^{87}$ Reichwein, 1931, p. 19.

${ }^{88}$ Reichwein, 1931, p. 21.

${ }^{89}$ Reichwein, 1931, p. 37. 
cambios y nuevas direcciones, indicaba este autor, para examinar "sus condiciones geográfico-históricas" ${ }^{\circ 0}$.

En su estudio sobre México, en este libro, Reichwein sitúa las dos variables de análisis: el espacio y el tiempo, características de la tradición geográfica alemana. Ocupan, en este orden, los primeros dos capítulos. En "El espacio" se situaban los mapas de síntesis de las tres zonas climáticas del espacio mexicano: la tierra fría, la tierra templada y la tierra caliente con la finalidad de conocer la "capacidad de cultivo" del país. En la formación del paisaje intervino la historia geológica, la formación del relieve, la actuación de la erosión en las formas montañosas y en las cuencas aluviales. El relieve del mundo rural lo asombraba: "Para el viajero, aquellas calderas llanas, junto a los grandiosos conos de los gigantescos volcanes, resultan las formas peculiares del suelo mejicano. Lo que más impresiona es el valle amplio y cerrado, con el volcán coronado de nieve en la bruma de la lejanía" ${ }^{\prime 1}$.

Ahí se fijaba en las tierras altas y la necesidad del riego, pues las lluvias eran menores desde Querétaro hasta San Luis Potosí, al igual que en los enormes territorios del norte que se continuaban con las grandes planicies de Arizona, Nuevo México y Texas. Por eso, ahí se formaba el paisaje del algodón, el trigo, la ganadería y la minería. Contrastaban los paisajes de las vertientes, la humedad del golfo se reflejaba en la "fertilísima tierra negra, que produce azúcar, café, tabaco y frutas en abundancia" ${ }^{92}$. En la vertiente occidental, de Colima a Sonora, actuaba una débil erosión y, en los bancos de arena con instalación del regadío artificial, crecían los frutos del trópico, tabaco, caña de azúcar y café; además era el espacio susceptible para los asentamientos humanos en los planes para la colonización en esa región.

El sur, hacia las tierras calientes, "nunca ha sido favorable para la colonización por sus condiciones climáticas y topográficas", se refiere a la "faja costera y llana", escasamente poblada, sin considerar los puertos, de la costa del golfo de México (con excepción de las plantaciones y la ganadería de Veracruz y Tabasco), la península de Yucatán, el istmo de Tehuantepec y las fajas costeras del Pacífico ${ }^{93}$. Al final del capítulo, Reichwein calculó las tierras de cultivo en relación con la colonización, uno de los principales resultados de su libro. Para la superficie agrícola eran: 124335 kilómetros cuadrados (6.26 \%), dato que calificó de "pobreza sorprendente" las de mayor interés para los colonos extranjeros, las demás tierras quedaban fuera de su consideración, es decir la extensión de los bosques: 165653 kilómetros cuadrados (8.34\%), los pastos: 487426 kilómetros cuadrados $(24.53 \%)$ y las tierras yermas o sin cultivos, que también descartaba, igual a: 1212459 kilómetros cuadrados (61.02\%).

En el capítulo de "La historia", Reichwein integraba una visión con una larga temporalidad, desde el siglo XV, de luchas e inestabilidad políticas hasta la época de cambios con su visita. En el devenir histórico insertaba un mapa de México como "campo de tensión" de los Estados Unidos. Ahí se mostraba la nueva espacialidad del poder de los Estados Unidos, del interés de Reichwein, integrada por una larga base por el norte, con dos vértices: al este, Portland (Maine), al oeste, Portland (Oregón) y cerraba, por el sur, el canal de Panamá. En el mapa quedaba definido un gran triángulo norteamericano, para Reichwein, el área de la expansión

\footnotetext{
${ }^{90}$ Reichwein, 1931, p. 38.

${ }^{91}$ Reichwein, 1931, p. 44. Este paisaje rural descrito por Reichwein en su libro era grabado por él mismo con la cámara de 16 milímetros. Véase la nota 82.

92 Reichwein, 1931, p. 50.

${ }^{93}$ Reichwein, 1931, p. 53.

${ }^{94}$ Reichwein, 1931, p. 56.
} 
de los Estados Unidos basada en el tráfico terrestre que circulaba por la red de carreteras de norte a sur y el marítimo que conectaba la flota de vapores de los Estados Unidos, a través del Canal de Panamá y la topografía de los ríos, las planicies y las montañas ${ }^{95}$ (figura 4).

Figura 4.

Mapa del "campo de tensión" de los Estados Unidos

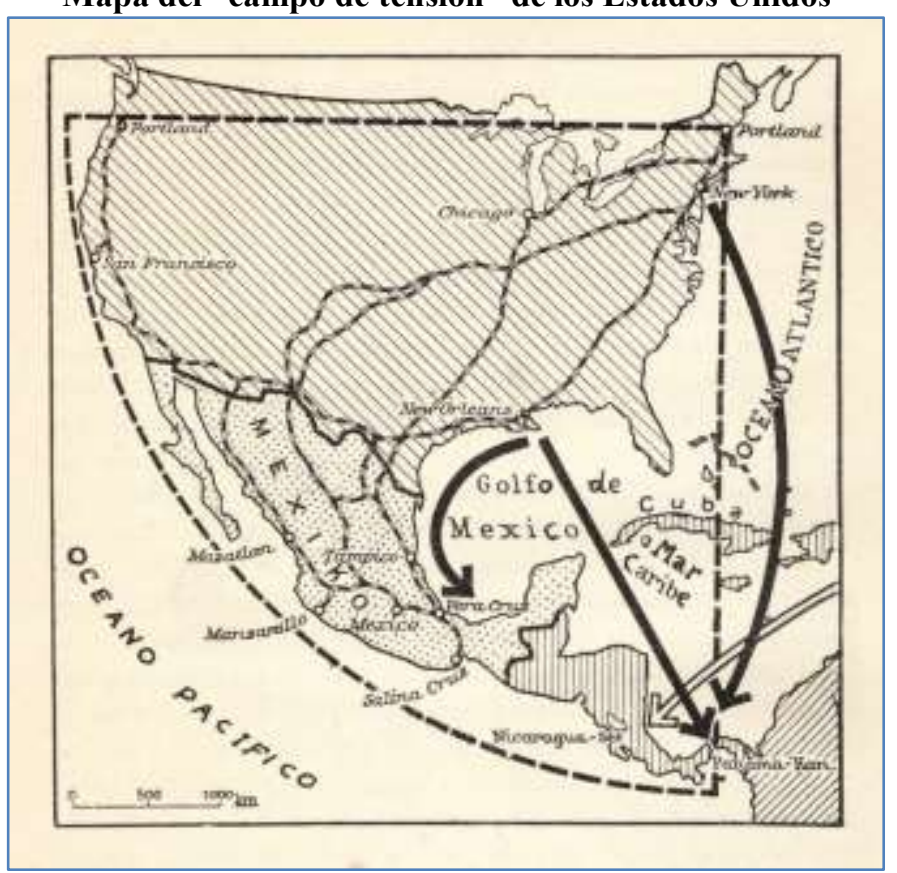

Fuente: Reichwein, 1931, p. 89.

De esta geografía política, Reichwein pasaba al problema agrario, la pugna política del momento y el movimiento obrero. Sin embargo, había dos temas en su obra que resaltaron para Reichwein: las relaciones de la Iglesia con el Estado y la lucha por el petróleo. Ambos episodios vividos por el autor, como ya se indicó. En su viaje, dichas relaciones alcanzaron un punto álgido con la prohibición, por parte del gobierno de Calles, de la "formación de partidos políticos y asociaciones sobre bases religiosas", la reacción de las organizaciones católicas, dentro y fuera de México, desató la guerra cristera. Reichwein, como se ha visto, se dio cuenta: la defensa de "Cristo Rey" llevó a los campesinos a la muerte en los campos de batalla y, ante los intereses encubiertos de la iglesia católica, añadió una crítica en su libro: lo que buscaba era el "interés político por alcanzar poder económico y público" que había perdido poco antes con la revolucion mexicana ${ }^{96}$.

La segunda arena abierta era el petróleo, una de las mayores riquezas en la economía mundial. Reichwein viajó a Tampico en el "Amassia", ahí estuvo seis días y regresó el 2 de junio de 1927 para Amberes. En esos días, pudo examinar directamente la situación petrolera de la región y ordenar unas reflexiones. La presión de los Estados Unidos le pareció imparable ante las dificultades que pasaba el limitado gobierno de Calles. La nue va organización económica a partir del dominio "de todos los minerales o todas las substancias" del subsuelo (artículo 27 de la nueva Constitución), tensaba las relaciones con los Estados Unidos debido a la afectación de las grandes firmas del "capital petrolífero extranjero". Para Reichwein tal escenario incidía en el futuro, no únicamente de México, sino de la economía que requería de estos energéticos para la producción. Las negociaciones se prolongaron más allá del viaje de

\footnotetext{
${ }^{95}$ Reichwein, 1931, p. 89.

${ }^{96}$ Reichwein, 1931, p. 238.
} 
Reichwein. Calles, al final, flexibilizó su intención de "mexicanizar" las empresas petroleras (lo que significaba al menos $50 \%$ del capital en manos mexicanas) y en ceder a la protección diplomática para los extranjeros de esta industria. Esto alejaba la ruptura de las relaciones diplomáticas entre los dos países y dejaba margen al gobierno de Calles para dirigir la atención a la educación, uno de los frentes pendientes del poder político.

\section{Conclusiones}

En este trabajo se han examinado los cambios de la cultura alemana hacia México a través de tres viajeros que permitieron identificar, en tres momentos, motivaciones diferentes en la construcción de una visión de conjunto para "incorporar al mundo conocido otras culturas y otras geografías" "97. México se posiciona en esta dirección interpretativa, primero, a través del mundo colonial y después en una organización política y social moderna y contemporánea del mundo. El contenido de las obras publicadas por los viajeros elegidos se basa en las experiencias subjetivas $\mathrm{y}$, en sus propuestas, hay una transición en los medios culturales aplicados por cada uno a lo largo de su viaje. Humboldt viajaba con el tono naturalista y a la vez científico, su viaje combinaba un conjunto de observaciones, de mediciones y una narrativa asociada a bases de datos y a la topografía vinculadas con la visual, a través de la simbolización del territorio con sus mapas contenidos en el atlas mexicano. Tal modelo científico se desvanece en la figura de Ratzel, quien viajaba con el tono periodístico y eliminaba el cálculo de coordenadas geográficas de la práctica de campo y la proyección de mapas. Reichwein ampliaba la narrativa escrita con un lenguaje visual apoyado por los mapas, a los que sumaba el uso de la fotografía y la película cinematográfica como una innovación para la docencia.

Cada uno de los viajeros alemanes y su obra sobre México ha sido vista bajo la propuesta de Livon-Grosman (2003) resumida a continuación. Humboldt, Ratzel y Reichwein tienen en común los lugares del viaje del Pacífico al golfo de México, la parte más comunicada y con facilidades de transporte. Desde ahí trazaron un cuadro sobre las características principales del espacio mexicano, como primera variable con la que abren los contenidos y el orden de su trabajo. La extensión del territorio y sus rasgos naturales (como volcanismo, montañas y valles) eran variables que situaban la importancia del país y motivo para su estudio; sin embargo, la dispersión de la población y el despoblamiento, para Humboldt de las franjas costeras y para Ratzel de las regiones norteñas, eran dos aspectos que perduraron en la visión de los viajeros. La agricultura era la siguiente variable que situaron en sus trabajos, les interesaban los productos de la tierra, tanto los de procedencia de la cultura europea como las especies de los climas cálidos, de ahí pasaron a los bosques, aunque su visión provenía nada más de la región central, por eso quedaron sorprendidos, tanto Humboldt como Ratzel, de los oyameles del Valle de México y su combinación con los amplios campos cerealeros y franjas de magueyes. Este paisaje, en las proximidades de la Ciudad de México, era uno de los aspectos que más valoraron y disfrutaron de su viaje. Tal visión se divide al ingresar al espacio interno de la capital mexicana, sobre este punto, sobresalen las opiniones de Humboldt y Ratzel. El primero alababa los espacios urbanos, las herencias novohispanas en cuanto a las obras realizadas, como la pavimentación e iluminación, poco antes de su llegada a la ciudad; en cambio, el segundo, era crítico del aspecto de la ciudad, le disgustaba su trazo y falta de higiene y confort. En este punto, Reichwein se apartaba de ambos y sus opiniones; por una parte, como se ha visto, no se sabe de su paso por la capital mexicana y, por otra, toda su obra era dedicada más a las características del mundo rural que al urbano.

\footnotetext{
${ }^{97}$ Livon-Grosman, 2003, p. 20.
} 
En cuanto a las referencias históricas, hay diferencias en su incorporación a su obra. En Humboldt hay referencias puntuales al pasado, algunas notas previas a su visita, mientras que Ratzel y Reichwein situaron la variable temporal en su análisis, una amplia y variada argumentación que conducía al tiempo presente mexicano. Ratzel trazaba una línea de luchas y caos entre las posturas políticas y la idea del colonialismo desde una óptica eurocéntrica y complaciente con que legitimaba una idea cultural e imperial para dominar el mundo; en cambio, Reichwein dirigió su mirada al pasado para analizar los problemas del mundo rural, como los actores agrarios, la propiedad de la tierra, las pugnas políticas del México posrevolucionario y, dentro de este cuadro, el movimiento obrero. En esta visión, desde luego, el paisaje surgido ante sus ojos ocupaba un lugar destacado y se une al resultado general o estudio del país como conjunto. Al respecto, destacaron los paisajes, tanto para Humboldt y Ratzel, de la riqueza minera, a lo que seguía el comercio y los negocios; la agricultura era vista por los tres con atención y en Reichwein el mundo rural ocupó una parte importante de su libro, ahí quedaba su hallazgo de la superficie agrícola disponible, que lo había decepcionado, ante la colonización e interés de los extranjeros,

Estas obras representaban una narrativa cíclica de intereses en el marco de contextos globales y de grandes intereses de su época hacia la espacialidad mexicana. Humboldt situaba la mirada alemana dentro del expansionismo europeo de la época y su obra era un "referente autorizado". Ahí quedaban anotadas "todas las riquezas naturales susceptibles de explotación" ofrecidas al mercado europeo en su expansión hacia América y Asia. En Ratzel hay un giro en la mirada alemana, esta vez, a la expansión de los Estados Unidos y su visión hacia México. Él contrastaba la escasa población, los malos caminos y una autoridad mexicana con casi nula influencia en los estados fronterizos con la acción civilizadora de los Estados Unidos sobre México, vista como un detonador para la llegada de los colonos alemanes, antes de esto, recomendaba dirigirse hacia las tierras de América del Sur. La temprana reflexión de este ideal en su pensamiento maduraba después sobre el interés nacional y las relaciones internacionales, a partir de posiciones centrales y periféricas de los Estados, tan influyentes en la construcción cultural de la unidad e imperialismo alemán. En Reichwein, en cambio, el mapa mostraba una consolidación del poder civilizador de los Estados Unidos, para él, a través de la red de carreteras, las redes técnicas que atravesaban las fronteras internacionales, el tráfico marítimo que conectaba la flota de vapores de los Estados Unidos con los puertos más importantes del Pacífico, el Caribe y, a través del canal de Panamá, con la costa este. Señalaba el final de una enemistad política y el cambio hacia una nueva relación con los Estados Unidos encaminada a un entendimiento y a importantes intercambios entre ambos países.

\section{Bibliografía}

AMLUNG, Ullrich. “...in der Entscheidung gibt es keine Umwege”. Adolf Reichwein (18981944) - Reformpädagoge, Sozialist, Widerstandskämpfer. Schüren: Marburg 1999a. 106 p.

AMLUNG, Ullrich. Adolf Reichwein 1898-1944. Ein Lebensbild des Reformpädagogen, Volkskundlers und Widerstandskämpfers. Verlag: Frankfurt am Main. 1999b. 632 p.

AZUELA BERNAL, Luz Fernanda. La valoración de Humboldt en los homenajes mexicanos del siglo XIX. In ZEA, Leopoldo et al. Humboldt y América Latina. Latinoamérica Fin de milenio. México: Instituto Panamericana de Geografía e Historia, 2000, vol. 15, p. 19-25. 
BASSIN, Mark. Friedrich Ratzel, 1844-1904. In FREEMAN, Thomas Walter. Geographers: Biobibliographical Studies, 1987, vol. 11, p. 123-132.

BECK, Hanno. Alexander von Humboldt. México: Fondo de Cultura Económica, 1971. 491 p.

BECK, Hanno. Contribución de Alexander von Humboldt a la cartografía. Ingelheim am Rhein: C. H. Boehringer Sohn. 1987, p. 239-248.

BERNECKER, Walther L. Literatura de viajes como fuente histórica para el México decimonónico: Humboldt, inversiones e intervenciones. Tzintzun. Revista de Estudios Históricos, 2003, n 38, p. 35-64.

BREUNING, Markus. Bibliographie über Alexander von Humboldt. Versuch einer Gesamtbibliographie nach Literaturauswertung- und Sammlung aus Europa, Nord-, Zentralund Südamerika. Bibliografía sobre Alejandro de Humboldt. Aproximación a una bibliografía completa y ordenada de las fuentes europeas y americanas. Bibliography on Alexander von Humboldt. Attempt of a complete and organized bibliography from European and American sources. Bern: Schweiz - Suiza, 2010.

CAPEL, Horacio. Filosofía y ciencia en la geografía contemporánea. Una introducción a la geografía. Barcelona: Ediciones del Serbal, 2012. 477 p.

CLAVAL, Paul. Histoire de la géographie. Paris: Presses Universitaires de France, 1995. 128 p.

COVARRUBIAS, José Enrique. Visión extranjera de México, 1840-1867. I. El estudio de las costumbres y de la situación social. México: Instituto de Investigaciones Históricas, Universidad Nacional Autónoma de México, 1998. 183 p.

COVARRUBIAS, José Enrique. La recepción de Humboldt en México, 1821-2000. Internationale Zeitschrift für Humboldt Studien - International Review for Humboldtian Studies - Revista Internacional de Estudios Humboldtianos - Revue d'Études Humboldtiennes, 2009, vol. 1, n¹9, p. 92-104.

COVARRUBIAS, José Enrique y SOUTO MANTECÓN, Matilde. Economía, ciencia y política. Estudios sobre Alexander von Humboldt a 200 años del Ensayo politico del reino de la Nueva España. México: Instituto de Investigaciones Dr. José María Luis Mora / Instituto de Investigaciones Históricas, UNAM, 2012, 291 p.

DUVIOLS, Jean-Paul et MINGUET, Charles. Humboldt, savant-citoyen du monde. Paris: Gallimard, 1994. 144 p.

ECKELMANN, Susanne. Adolf Reichwein 1898-1944. LeMO Lebendiges Museum Online, [En línea]. Bonn: Stiftung Deutsches Historisches Museum, 24 de noviembre 2014. $<$ https://www.dhm.de/lemo/biografie/biografie-adolf-reichwein.html $>[31$ de diciembre 2015].

HOLL, Frank. Alejandro de Humboldt en México. México: Instituto Nacional de Antropología e Historia - Instituto Goethe, 1997. 217 p. 
HOLL, Frank. Alejandro de Humboldt - una nueva visión del mundo. En conmemoración al bicentenario de la llegada de Humboldt a México. México: Universidad Nacional Autónoma de México, 2003. 207 p.

HOLT-JENSEN, Arild. Geografía. Historia y conceptos. Barcelona: Ediciones Vicens Vives, 1992. $236 \mathrm{p}$.

HUMBOLDT, Alejandro de. "Correspondencia mexicana de Humboldt, 1803-1804". In WIONCZEK, Miguel S. Alejandro de Humboldt. Tablas Geográficas Políticas del Reino de la Nueva España y Correspondencia Mexicana. México: Dirección General de Estadística. 1970, p. 73-142.

HUMBOLDT, Alexander von. Atlas geographique et physique du royaume de la nouvelleespage denominado también por el autor Atlas de México. México: Fondo de Cultura Económica, 1971.

HUMBOLDT, Alejandro de. Ensayo político sobre el reino de la Nueva España. México: Editorial Porrúa, 1984. 696 p.

HUMBOLDT, Alexander von. Cartas americanas. Caracas: Biblioteca Ayacucho, 1989. 308 p.

ITA RUBIO, Lourdes de y SÁNCHEZ DÍAZ, Gerardo. Humboldt y otros viajeros en América Latina. Morelia: Instituto de Investigaciones Históricas, Universidad Michoacana de San Nicolás de Hidalgo, 2006. 413 p.

ITA RUBIO, Lourdes de. Organización del espacio en el México colonial: puertos, ciudades y caminos. Morelia: Instituto de Investigaciones Históricas, Universidad Michoacana de San Nicolás de Hidalgo, 2012. 425 p.

JIMÉNEZ CODINACH, Guadalupe. Viajeros europeos del siglo XIX en México. México: Fomento Cultural Banamex, 1996. 265 p.

KRAFT, Tobias. La agenda de Alexander von Humboldt. Revista Humboldt, 2013, n 159, p. 18-19.

KRAFT, Tobias. Alejandro de Humboldt y el giro digital: desafíos para la edición de manuscritos históricos. MERIDIONAL Revista Chilena de Estudios Latinoamericanos, 2015, $\mathrm{n}^{\circ} 5$, p. 59-76.

LINGELBACH, Karl Christoph und AMLUNG, Ullrich. Adolf Reichwein. Pädagogische Schriften. Kommentierte Werkausgabe in fünf Bänden. 3. Schriften zur Lehrerbildung und frühen Schulpädagogik, 1930 - 1936. Bad Heilbrunn: Klinkhardt, 2011. 624 p.

LIVINGSTONE, David. The Geographical Tradition. Episodes in the History of a Contested Enterprise. Oxford: Blackwell, 1993. 434 p.

LIVON-GROSMAN, Ernesto. Geografías imaginarias. El relato de viaje y la construcción del espacio patagónico. Rosario: Beatriz Viterbo Editora, 2003. 208 p. 
LÓPEZ, Damián. La guerra cristera (México, 1926-1929). Una aproximación historiográfica. Historiografías, 2011, n 1, p. 35-52.

MARTÍNEZ, Miguel. Mapa General de la República Mexicana. Con expresión de sus líneas de Ferrocarriles, Vapores y Faros existentes. México: Mapoteca Manuel Orozco y Berra. Colección General, República Mexicana, varilla CGRM01, nº de clasificador: 61-CGE-7216A. 70 x 94 centímetros, escala gráfica, 1928.

MENDOZA VARGAS, Héctor. Lecturas Geográficas Mexicanas. Siglo XIX. (Selección y Estudio Introductorio), México: UNAM-Coordinación de Humanidades, 2007. 168 p.

MENTZ DE BOEGE, Brigida Margarita von. México en el siglo XIX visto por los alemanes. México: Instituto de Investigaciones Históricas. Universidad Nacional Autónoma de México, 1982. $477 \mathrm{p}$.

MORAES, Antonio Carlos Robert. Ratzel, São Paulo: Editora Ática, 1990. 200 p.

ORTEGA Y MEDINA, Juan Antonio. Estudio preliminar. In HUMBOLDT, Alejandro de. Ensayo político sobre el reino de la Nueva España. México: Editorial Porrúa, 1984, p. IXLIII.

ORTEGA Y MEDINA, Juan Antonio. Zaguán abierto al México republicano (1820-1830), William T. Penny. México: Universidad Nacional Autónoma de México, Instituto de Investigaciones Históricas, 1987. 216 p.

ORTEGA Y MEDINA, Juan Antonio. Científicos extranjeros en el México del siglo XIX. Estudios de Historia Moderna y Contemporánea de México, 1988, vol. 11, p. 13-20.

PEREZ MEJÍA, Ángela. Alexander von Humboldt: los silencios y complicidades de la cartografía. La geografía de los tiempos difíciles: escritura de viajes a Sur América durante los procesos de independencia 1780-1849. Medellín: Editorial Universitaria de Antioquia, 2002. p. 47-94.

PINZÓN RÍOS, Guadalupe. Una descripción de las costas del Pacífico novohispano del siglo XVIII. Estudios de Historia Novohispana, 2008, vol. 39, p. 157-182.

PINZÓN RÍOS, Guadalupe. Los mapas del Pacífico novohispano. Apropiación y defensa de los litorales durante el siglo XVIII. In MENDOZA VARGAS, Héctor y LOIS, Carla. (Coord.). Historias de la cartografía iberoamericana, México: Universidad Nacional Autónoma de México, Instituto de Geografía, Instituto Nacional de Geografía y Estadística, 2009. p. 183-210,

PINZÓN RÍOS, Guadalupe. Puertos y litorales novohispanos en las descripciones y críticas de Humboldt. In COVARRUBIAS, José Enrique y SOUTO, Matilde. (Ed.). Economía, ciencia y política. Estudio sobre Alexander von Humboldt a 200 años del Ensayo Político sobre el Reino de la Nueva España, México: Instituto de Investigaciones Dr. José María Luis Mora, Universidad Nacional Autónoma de México, Instituto de Investigaciones Históricas, 2012. p.185-218. 
POBLETT MIRANDA, Martha. Viajeros en el siglo XIX. México: Consejo Nacional para la cultura y las artes, 2000. $64 \mathrm{p}$.

PRECIADO ZAMORA, Julia. Los cristeros del volcán y los pacíficos de La Esperanza. Signos Históricos, 2008, n 19, p. 68-93.

RADKAU, Verena, Relaciones diplomáticas e injerencia política. In MENTZ, Brígida von, RADKAU, Verena, SCHARRER, Beatriz y TURNER, Guillermo. Los pioneros del imperialismo alemán en México. México: Centro de Investigaciones y Estudios Superiores en Antropología Social, 1982. p. 287-329.

RAMÍREZ RODRÍGUEZ, Rodolfo. Atisbo historiográfico de la literatura viajera decimonónica en México. Trashumante. Revista Americana de Historia Social, 2013, vol. 1, p. 114-136.

RATZEL, Friedrich. Desde México. Apuntes de viaje de los años 1874-1875. México: Editorial Herder, 2009. 453 p.

REICHWEIN, Adolfo. El despertar de Méjico. Madrid: Editorial Cenit, 1931. 294 p.

REICHWEIN, Adolf. Maisernte in Mexiko. Berlin: Naturfil Hubert Schonger, 1936

[Reichsstelle für den Unterrichtsfilm: F 110]

https://www.youtube.com/watch?v=7gfvcJPgQ8o > [17 de enero 2016].

REICHWEIN, Roland. Adolf Reichweins Reise durch Mexico 1927. Reichwein Forum, Impressum, 2011, n 11 , p. 20-21.

SÁNCHEZ DÍAZ, Gerardo. La estancia y recorridos de Alexander von Humboldt en la Nueva España. In HUMBOLDT, Alejandro de. Tablas Geográfico-Políticas de la Nueva España. Morelia: Instituto de Investigaciones Históricas, Universidad Michoacana de San Nicolás de Hidalgo, 2005. p. 13-40.

SANDNER, Gerhard and RÖSSLER, Mechtild. Geography and Empire in Germany, 18711945. In GODLEWSKA, Anne and SMITH, Neil. Geography and Empire. Oxford: Basil Blackwell, 1994. p. 115-127.

SANTONJA, Gonzalo. Breve perfil de la editorial Cenit (Madrid, 1928-1936). 1616: Anuario de la Sociedad Española de Literatura General y Comparada, 1983-1984, vol. V, p. 129-139.

SCHLÖGEL, Karl. Mapas monocromos: El Estado nacional, In SCHLÖGEL, Karl. En el espacio leemos el tiempo. Sobre Historia de la civilización y geopolítica. Madrid: Ediciones Siruela, 2007. p. 197-208.

SCHULZ, Ursula. Adolf Reichwein: (3 Okt. 1898 - 20 Okt. 1944). Bibliographie Seiner Schriften. Bremen: Volkshochschule, 1966. 56 p.

SEEMANN, Jörn. Friedrich Ratzel entre Tradições e Traduções. Terra Brasilis (Nova Série). $\mathrm{n}^{\circ} 1,2012,<\mathrm{http} / / /$ terrabrasilis.revues.org/180> 5 de noviembre de 2012. [12 enero 2016]. DOI : 10.4000/terrabrasilis. 180

STODDART, David. On Geograph. And Its History. Oxford: Basil Blackwell, 1986. 335 p. 
TRABULSE, Elías. Tablas Geográficas Políticas del Reyno de Nueva España. México: Siglo XXI, 2003. $335 \mathrm{p}$.

TURNER, Guillermo. Ideología de la clase dominante mexicana y del grupo alemán sobre la inmigración y colonización europea de México en el siglo XIX (1823-1874). In MENTZ, Brígida von, RADKAU, Verena, SCHARRER, Beatriz y TURNER, Guillermo. Los pioneros del imperialismo alemán en México. México: Centro de Investigaciones y Estudios Superiores en Antropología Social, 1982. p. 365-409.

UNWIN, Tim. El lugar de la geografía. Madrid: Cátedra, 1995. 342 p.

WEHL. Heidrun. Vom Wandervogel zum Mitglied des Kreisauer Kreises ein Beitrag zur (inneren) Biographie Adolf Reichweins in Selbstzeugnissen und Briefen. Berlin: DrosteHülshoff-Schule, 2006. 30 p.

ZAMUDIO, Luz Elena. Espacio, viajes y viajeros. México: Universidad Autónoma Metropolitana-Iztapalapa, 2004. 354 p.

ZERMEÑO, Guillermo. La mirada de un naturalista. In RATZEL, Friedrich. Desde México. Apuntes de viaje de los años 1874-1875. México: Editorial Herder, 2009. p. 15-34.

ZERMEÑO, Guillermo. Friedrich Ratzel en México (1874-1875): génesis y trasfondo filosófico de la obra de un naturalista alemán. In KOHUT, Karl, MAYER, Alicia, MENTZ, Brígida von y TORALES, María Cristina. Alemania y el México independiente. Percepciones mutuas, 1810-1910. México: Editorial Herder, 2010. p. 157-172.

(c) Copyright: Héctor Mendoza Vargas, 2016.

(C) Copyright Scripta Nova, 2016.

Ficha bibliográfica:

MENDOZA VARGAS, Héctor. La mirada alemana sobre México en tres viajeros: Alexander von Humboldt (1769-1859), Friedrich Ratzel (1844-1904) y Adolf Reichwein (1898-1944). Scripta Nova. Revista Electrónica de Geografía y Ciencias Sociales. [En línea]. Barcelona: Universidad de Barcelona, 15 de septiembre de 2016, vol. XX, nº 544. <http://www.ub.es/geocrit/sn/sn-544.pdf>. ISSN: 1138-9788. 